\title{
Ghrelin and Nicotine Stimulate Equally the Dopamine Release in the Rat Amygdala
}

\author{
Miklós Palotai · Zsolt Bagosi • Miklós Jászberényi • \\ Krisztina Csabafi · Roberta Dochnal · Máté Manczinger • \\ Gyula Telegdy · Gyula Szabó
}

Received: 16 May 2013/Revised: 26 June 2013/ Accepted: 28 June 2013/Published online: 9 July 2013

(C) Springer Science+Business Media New York 2013

\begin{abstract}
The orexigenic peptide ghrelin plays a prominent role in the regulation of energy balance and in the mediation of reward processes and reinforcement for addictive drugs, such as nicotine. Nicotine is the principal psychoactive component in tobacco, which is responsible for addiction and relapse of smokers. Ghrelin and nicotine activates the mesolimbicocortical dopaminergic pathways via growth hormone secretagogue receptors (GHS-R1A) and nicotinic acetylcholine receptors (nAchR), respectively, resulting in the release of dopamine in the nucleus accumbens, the amygdala and the prefrontal cortex. In the present study an in vitro superfusion of rat amygdalar slices was performed in order to investigate the direct action of ghrelin and nicotine on the amygdalar dopamine release. Ghrelin increased significantly the dopamine release from the rat amygdala following electrical stimulation. This effect was inhibited by both the selective GHS-R1A antagonist GHRP6 and the selective nAchR antagonist mecamylamine. Under the same conditions, nicotine also increased significantly the dopamine release from the rat amygdala. This effect was antagonized by mecamylamine, but not by GHRP-6. Co-administration of ghrelin and nicotine induced a similar increase of amygdalar dopamine release. This stimulatory effect was partially reversed by both GHRP-6 and mecamylamine. The present results demonstrate that both ghrelin and nicotine stimulates directly the dopamine release in the amygdala, an important dopaminergic target area of the mesolimbicocortical pathway.
\end{abstract}

M. Palotai · Z. Bagosi ( $₫) \cdot$ M. Jászberényi · K. Csabafi · R. Dochnal · M. Manczinger · G. Telegdy · G. Szabó Department of Pathophysiology, Faculty of Medicine, University of Szeged, Semmelweis Str. 1, Szeged 6725, Hungary e-mail: bagosi@hotmail.com
Keywords Ghrelin · Nicotine - Dopamine - Amygdala Superfusion

\section{Introduction}

Ghrelin is a 28 -amino acid orexigenic peptide, which was originally isolated from the rat stomach $[1,2]$. It acts on the growth hormone secretagogue receptor (GHS-R), which has two isoforms (GHS-R1A and GHS-R1B) [3]. GHS$\mathrm{R} 1 \mathrm{~A}$, apart from $\mathrm{GH}$ release, was proved to mediate food intake and energy balance, reward, addiction, memory, arousal and neuroprotection [4]. GHS-R1B is thought to regulate/inhibit the actions of GHS-R1A [5].

Nicotine is the principal psychoactive component in tobacco, which is responsible for addiction and relapse of smokers [6]. Nicotine exerts its effects on the central nervous system by the activation of nicotinic acetylcholine receptors (nAchRs) [7]. The dopaminergic neurons of the mesencephalon express a variety of nAchR subtypes which, when activated by nicotine, promote a sustained increase in dopamine release in the target areas. This process was found essential to the development of nicotine addiction [8] and could be inhibited by the non-selective, competitive nAchR antagonist mecamylamine [9].

Nicotine, infused directly into the dopaminergic target areas, elevates dopamine release from the nerve terminals and this effect is blocked by mecamylamine [9]. The principal dopaminergic pathways arise from the mediobasal hypothalamus (tuberoinfundibular pathway), ventral tegmental area (VTA, mesolimbicocortical pathways) and the substantia nigra (mesostriatal pathway) [10]. The VTA gives rise to the mesolimbicocortical pathway and innervates the nucleus accumbens (NAcc), the amygdala, 
especially the central (CeA) and the basolateral (BLA) amygdalar nuclei and the prefrontal cortex [11-13].

Previous articles suggested that ghrelin activates the cholinergic-dopaminergic reward link [14-16]. This reward link encompasses the cholinergic afferent projection from the laterodorsal tegmental area (LDTg) to the VTA and the dopaminergic mesolimbic pathway projecting from the VTA to the NAcc [17]. Several lines of evidence support that this link mediates the reward and reinforcement for both natural and artificial rewards and addictive drugs, such as nicotine [18-20]. Ghrelin presumably, via activation of this reward link, increases the incentive value of motivated behaviors such as reward seeking [16].

Recent articles demonstrated that ghrelin has a prominent impact on the amygdala, an important dopaminergic target area of the mesolimbicocortical pathway [21-23]. The role of amygdala in reward mechanisms and drug addiction is underlined by the anatomical concept of the extended amygdala circuit, which consists of the central nucleus of amygdala (CeA), the bed nucleus of stria terminalis (BNST) and the shell of NAcc [12]. The nuclei of extended amygdala circuit have similar cell morphology, immunohistochemistry, and common afferent (VTA and limbic areas, such as the hippocampus, the basolateral amygdala (BLA), the midbrain, and the lateral hypothalamus) and efferent projections (VTA, the ventral pallidum, the brainstem and the lateral hypothalamus) [24] modulating drug reward and addiction to drugs, such as nicotine $[25,26]$.

Recently published studies have focused upon the action of ghrelin on the accumbal dopamine release and its interaction with addictive drugs. In these studies, ghrelin was administered peripherally, intracerebroventricularly or locally, into the LDTg or the VTA [14-16]. However, these studies provided no evidence about the direct effect of ghrelin on the dopaminergic target areas of the VTA, such as the amygdala. Therefore, in this study an in vitro superfusion of rat amygdalar slices was performed in order to investigate the action of ghrelin and nicotine on the amygdalar dopamine release. In the present experiments ghrelin and nicotine were applied directly into the amygdala, in single or in co-administration.

\section{Materials and Methods}

Animals Used

Male Wistar rats weighing 150-250 g were used. During the experiments every effort was made to limit the number of animals used, and to minimize animal suffering. The animals were kept according to the rules of the Ethical
Committee for the Protection of Animals in Research (University of Szeged, Hungary).

\section{Chemicals Used}

Rat amygdalar slices were prepared, incubated and superfused with Krebs solution (composition: $113 \mathrm{mM} \mathrm{NaCl}$, $4.7 \mathrm{mM} \mathrm{KCl}, 1.2 \mathrm{mM} \mathrm{MgSO}_{4}, 25 \mathrm{mM} \mathrm{NaHCO}_{3}, 11.5 \mathrm{mM}$ glucose, $1.2 \mathrm{mM} \mathrm{KH}_{2} \mathrm{PO}_{4}, 2.5 \mathrm{mM} \mathrm{CaCl}_{2}$, pH 7.4; Reanal, Hungary). $\left[{ }^{3} \mathrm{H}\right]$ dopamine $\left(\left[{ }^{3} \mathrm{H}\right] \mathrm{DA}\right)$ (specific activity: 14 $\mathrm{Ci} / \mathrm{mmol}$ ) was purchased from PerkinElmer Inc., USA. The slices were pretreated with $100 \mu \mathrm{M}$ mecamylamine, a nonselective nAch receptor antagonist (Sigma-Aldrich Inc., USA) or with $1 \mu \mathrm{M}$ [D-Lys3]-growth hormone releasing peptide-6 (GHRP-6), a selective GHS-R1A antagonist (Sigma-Aldrich Inc., USA), then treated with $1 \mu \mathrm{M}$ ghrelin (Bachem Inc., Switzerland) or $100 \mu \mathrm{M}$ nicotine (Bachem Inc., Switzerland) or both.

\section{Experimental Procedures}

An in vitro superfusion method [27, 28] was utilized to determine the effects of ghrelin and nicotine on amygdalar dopamine release. The rats were decapitated and their brains were rapidly removed. The amygdalae were isolated and dissected in a Petri dish filled with ice-cold Krebs solution. The amygdalae were prepared according to the Stereotaxic atlas of the rat brain [29]. The left and right poles of the temporal lobes were dissected in the frontal plane at the anterior (approximately $1.5 \mathrm{~mm}$ rostrally from the bregma) and the posterior (approximately $2 \mathrm{~mm}$ caudally from the bregma) borders of the amygdalae. The amygdalae were then decapsulated from the surrounding white matter with the help of a stereomicroscope. External skull reference values were extrapolated to brain coordinates using the limits of the hemispheres such as, the anterior poles and the fissure between the cerebrum and the cerebellum. In the sagittal plain, the bregma is approximately in $4 \mathrm{~mm}$ distance from the anterior pole, therefore the reference coordinates can be calculated with subtracting $4 \mathrm{~mm}$ from the bregma value according to the abscissa. The extracted amygdalae were cut with a McIlwain tissue chopper and slices of $300 \mu \mathrm{M}$ were produced. The slices were incubated for $30 \mathrm{~min}$ in $8 \mathrm{ml}$ of Krebs solution, submerged in a water bath at $37{ }^{\circ} \mathrm{C}$ and gassed through a single use needle with a mixture of $5 \% \mathrm{CO}_{2}$ and $95 \% \mathrm{O}_{2}$. During the incubation, the medium was supplemented with $0.15 \mu \mathrm{mol}\left[{ }^{3} \mathrm{H}\right] \mathrm{DA}$. The total amount of radioactivity used for labeling tissue dopamine stores was $0.042 \mu \mathrm{Ci} / \mathrm{ml}$ and the tissue content of radioactivity was $0.386 \mu \mathrm{Ci} / \mathrm{ml}$. Two tritiated slices were transferred to each of the four cylindrical perspex chambers of the superfusion system (Experimetria Ltd., Hungary). A multichannel peristaltic pump 
(Gilson Minipuls 2) was used to maintain a constant superfusion rate of $300 \mu \mathrm{l} / \mathrm{min}$. The superfusion was performed for $30 \mathrm{~min}$ to allow tissue equilibrium, then the samples were collected for $32 \mathrm{~min}$ in Eppendorf tubes by a multichannel fraction collector (Gilson FC 203B). 20 min prior to sample collecting, the slices were pretreated with $100 \mu \mathrm{M}$ mecamylamine or with $1 \mu \mathrm{M}$ GHRP-6. $10 \mathrm{~min}$ prior to sample collecting, the slices were treated with $1 \mu \mathrm{M}$ ghrelin, $100 \mu \mathrm{M}$ nicotine or combined. Gold electrodes were attached to both halves of the superfusion chambers and connected to an ST-02 electrical stimulator (Experimetria Ltd., Hungary). Two minutes after the sample collection had started, electrical stimulation consisting of square-wave impulses (total duration: $2 \mathrm{~min}$, voltage: $100 \mathrm{~V}$, pulse length: $5 \mathrm{~ms}$, frequency: $10 \mathrm{~Hz}$ ) were delivered to each of the four chambers. The remnants of the superfused brain slices were solubilized in $200 \mathrm{ml}$ of Krebs solution, using an ultrasonic homogenizer (Branson Sonifier 250, Labequip Ltd., Canada). The radioactivity in the fractions and the homogenized tissue samples was measured with a liquid scintillation spectrometer (Tri-carb 2100TR, Packard, USA) and expressed in count per minute (CPM) after the addition of $3 \mathrm{ml}$ of scintillation fluid (Ultima Gold, Perkin Elmer Inc., USA). 16 fractions were collected and $200 \mu \mathrm{l}$ were extracted from each fraction to determine the fractional $\left[{ }^{3} \mathrm{H}\right] \mathrm{DA}$ release. The fractional $\left[{ }^{3} \mathrm{H}\right] \mathrm{DA}$ release was calculated as percentage of the radioactivity present in the collected sample relative to the total radioactivity of the corresponding tissue. The statistical analysis was performed for each fraction, but the most significant differences have been observed at the $14 \mathrm{~min}$ fractions.

\section{Statistical Analysis}

Statistical analysis of the results was performed by repeated measure analysis of variance (RMANOVA, Statistica v5.0, StatSoft Inc.) followed by Tukey's post hoc comparison test. Only the mean percentages were plotted and the standard error of the mean (SEM) is given in the figure captions. The differences between groups were examined by Tukey's post hoc comparison test, and a probability level of 0.05 or less was accepted as indicating a statistically significant difference.

\section{Results}

Ghrelin increased significantly the fractional $\left[{ }^{3} \mathrm{H}\right] \mathrm{DA}$ release from rat amygdala slices following electrical stimulation $\left[\mathrm{F}_{14 \min }(1,10)=82.4272, p<0.05\right.$ for ghrelin versus control]. This effect was completely reversed by GHRP-6 $\left[\mathrm{F}_{14 \min }(1,10)=62.1864, p<0.05\right.$ for ghrelin + GHRP-6 versus ghrelin], and it was partially reversed by mecamylamine $\left[\mathrm{F}_{14 \min }(1,10)=16.0746, p<0.05\right.$ for ghrelin + mecamylamine versus ghrelin] (Fig. 1).

Nicotine also increased significantly the fractional $\left[{ }^{3} \mathrm{H}\right] \mathrm{DA}$ release from rat amygdala slices following electrical stimulation $\left[\mathrm{F}_{14 \min }(1,10)=40.5000, p<0.05\right.$ for nicotine versus control]. This effect was inhibited significantly by mecamylamine $\left[\mathrm{F}_{14 \min }(1,10)=28.5480, p<0.05\right.$ for nicotine + mecamylamine versus nicotine], but it was not influenced considerably by $\operatorname{GHRP}-6\left[\mathrm{~F}_{14 \min }(1,10)=1.1732\right.$, $p=0.3041$ for nicotine + GHRP-6 versus nicotine] (Fig. 2).

Ghrelin combined with nicotine elevated significantly the fractional $\left[{ }^{3} \mathrm{H}\right] \mathrm{DA}$ release from rat amygdala slices following electrical stimulation $\left[\mathrm{F}_{14 \min }(1,10)=54.6615\right.$, $p<0.05$ for ghrelin + nicotine versus control]. Coadministration of ghrelin and nicotine produced a similar increase of amygdalar dopamine to that induced by single administration of ghrelin or nicotine. The elevation of the amygdalar dopamine release observed in the case of combined treatment was reduced by pretreatment with mecamylamine $\left[\mathrm{F}_{14 \min }(1,10)=25.6499, p<0.05\right.$ for ghrelin + nicotine + mecamylamine versus ghrelin + nicotine $]$ or with $\operatorname{GHRP}-6\left[\mathrm{~F}_{14 \min }(1,10)=20.2275\right.$, $p<0.05$ for ghrelin + nicotine + GHRP-6 versus ghrelin + nicotine] (Fig. 3).

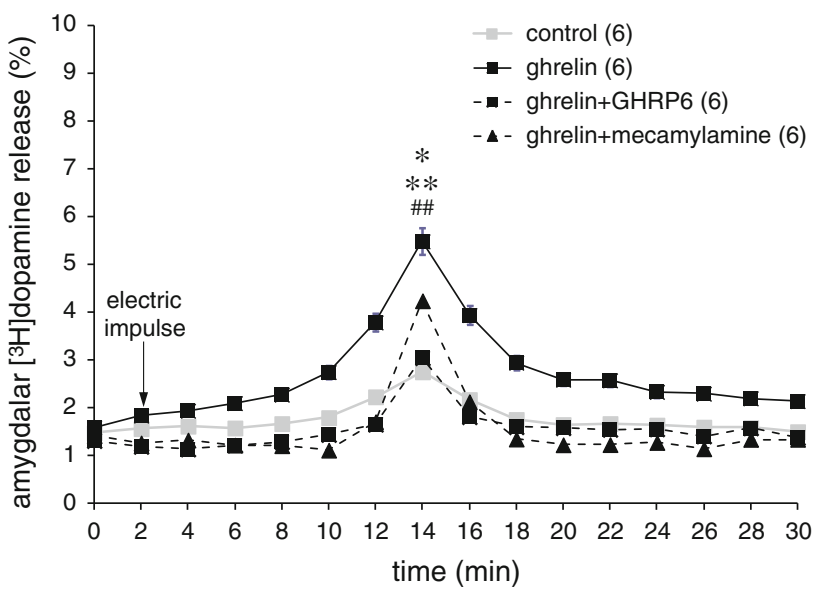

Fig. 1 The effects of mecamylamine and GHRP-6 on the ghrelininduced dopamine release in rat amygdala. $1 \mu \mathrm{M}$ ghrelin increased significantly the fractional $[3 \mathrm{H}]$ dopamine release from rat amygdala slices following electrical stimulation. This effect was completely reversed by $1 \mu \mathrm{M}$ GHRP-6, and partially reversed by $100 \mu \mathrm{M}$ mecamylamine. Values are presented as mean percentages \pm SEM for each of the 2 min samples; the numbers in brackets indicate the numbers of slices. Statistical analysis of the results was performed by repeated measure analysis of variance (RMANOVA, Statistica v5.0, StatSoft Inc.) followed by Tukey's post hoc comparison test. $* p<0.05$ ghrelin versus control; ${ }^{\# \#} p<0.05$ ghrelin + mecamylamine versus ghrelin alone; $* * p<0.05$ ghrelin + GHRP-6 versus ghrelin alone 


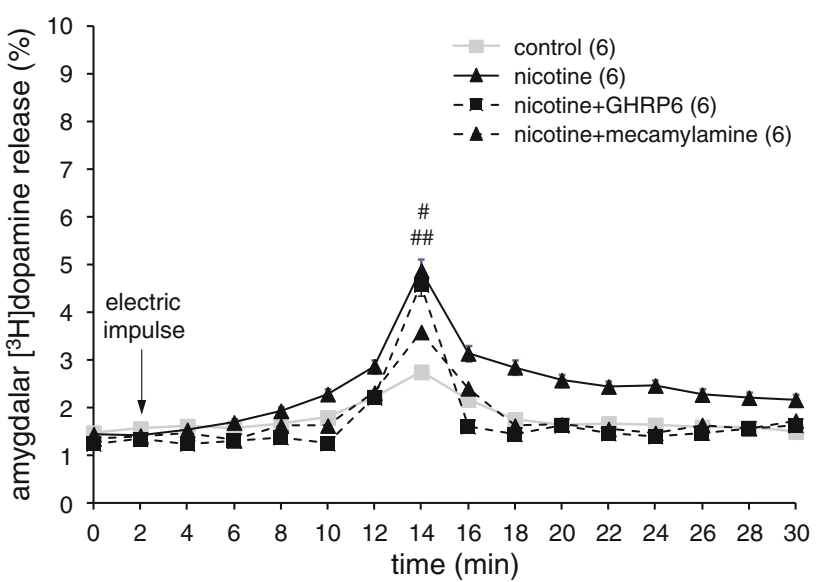

Fig. 2 The effects of mecamylamine and GHRP-6 on the nicotineinduced dopamine release in rat amygdala. $100 \mu \mathrm{M}$ nicotine enhanced significantly the fractional $[3 \mathrm{H}]$ dopamine release from rat amygdala slices following electrical stimulation. This effect was inhibited by $100 \mu \mathrm{M}$ mecamylamine, but was not influenced by $1 \mu \mathrm{M}$ GHRP-6. Values are presented as mean percentages \pm SEM for each of the 2 min samples; the numbers in brackets indicate the numbers of slices. Statistical analysis of the results was performed by repeated measure analysis of variance (RMANOVA, Statistica v5.0, StatSoft Inc.) followed by Tukey's post hoc comparison test. ${ }^{\#} p<0.05$ nicotine versus control; ${ }^{\# \#} p<0.05$ nicotine + mecamylamine versus nicotine alone

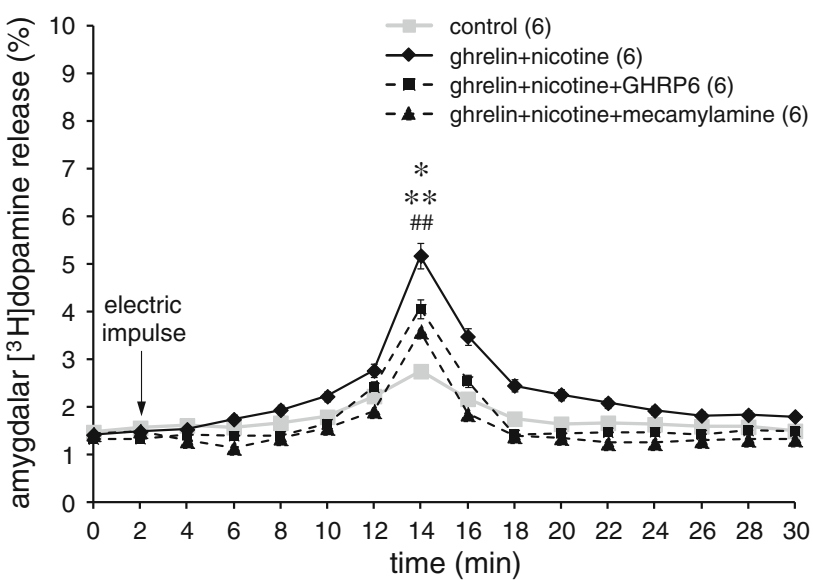

Fig. 3 The effects of mecamylamine and GHRP-6 on the coadministered ghrelin and nicotine induced dopamine release in rat amygdala. Combined treatment with $1 \mu \mathrm{M}$ ghrelin and $100 \mu \mathrm{M}$ nicotine elevated significantly the fractional $[3 \mathrm{H}]$ dopamine release from rat amygdala slices following electrical stimulation. This effect was reduced partially by pretreatment with both $100 \mu \mathrm{M}$ mecamylamine and $1 \mu \mathrm{M}$ GHRP- 6 . Values are presented as mean percentages \pm SEM for each of the 2 min samples; the numbers in brackets indicate the numbers of slices. Statistical analysis of the results was performed by repeated measure analysis of variance (RMANOVA, Statistica v5.0, StatSoft Inc.) followed by Tukey's post hoc comparison test. ${ }^{*} p<0.05$ ghrelin + nicotine versus control; ${ }^{\# \#} p<0.05$ ghrelin + nicotine + mecamylamine versus ghrelin + nicotine; ${ }^{* *} p<0.05$ ghrelin + nicotine + GHRP- 6 versus ghrelin + nicotine

\section{Discussion}

The present study demonstrates for the first time that ghrelin stimulates locally the dopamine release in the rat amygdala. This stimulation is mediated by GHS-R1A, as GHR-P6 inhibited completely the ghrelin-induced amygdalar dopamine release. There is a growing body of evidence revealing that ghrelin plays a prominent role in reward and reinforcement for both natural and artificial rewards and addictive drugs, such as nicotine [14, 16, 19]. Previous studies suggested that this role is accomplished by the activation of the cholinergic-dopaminergic reward link, which encompasses the afferent cholinergic projection from the LDTg to the VTA and the mesolimbic dopaminergic projection from the VTA to the NAcc [14-16]. Prior experiments showed that local administration of ghrelin into the LDTg or the VTA stimulates the dopamine release from the nerve terminals of the mesencephalic dopaminergic neurons, such as the NAcc $[16,18,30]$. The increase of accumbal dopamine release was reduced by different nicotinic receptor antagonists [16, 31]. Our experiments proved for the first time the direct action of ghrelin on the amygdalar dopamine release. This process can be either transmitted by presynaptic receptors or by cholinergic interneurons, which is supported by the inhibitory activity of selective nAchR antagonist. The amygdalar interaction of ghrelin with GABA and glutamate cannot be excluded either [22, 32]; this is suggested by the residual activity observed in the presence of ghrelin and mecamylamine.

The present study correlates with previous ones, demonstrating that nicotine stimulates the dopamine release in the terminal fields of the mesencephalic dopaminergic pathways, such as the ventral striatum (caudate-putamen), the dorsal striatum (NAcc) and the amygdala [33-35]. The stimulatory effect of nicotine is mediated by several $\mathrm{nAchR}$ subtypes expressed on dopaminergic cell bodies $(\alpha 4 \alpha 5 \beta 2$, $\alpha 4 \alpha 6 \alpha 5 \beta 2, \alpha 7)$ and on axon terminals $(\alpha 4 \beta 2, \alpha 4 \alpha 5 \beta 2$, $\alpha 6 \beta 2 \beta 3, \alpha 4 \alpha 6 \beta 2 \beta 3$ ) [6]. The latter ones are localized in these dopaminergic target areas, including the NAcc and amygdala, which represent the principal relay stations in the extended amygdala circuit [10, 12]. Along with the cholinergic-dopaminergic reward link, the extended amygdala circuit plays a prominent role in drug reward and drug addiction $[16,36]$. Besides the functional correlation, there is a strong anatomical connection between these two systems. On one hand, the NAcc is a common nucleus of the two systems. On the other hand, the dopaminergic neurons of the VTA innervate each nuclei of the extended amygdala circuit (the NAcc, the BNST and the CeA) [10]. In addition, most of these nuclei express GHS-R1A and nAchRs [6, 22, 37, 38] (Fig. 4). Mecamylamine blocked the effect of nicotine, without a doubt, significantly, but 


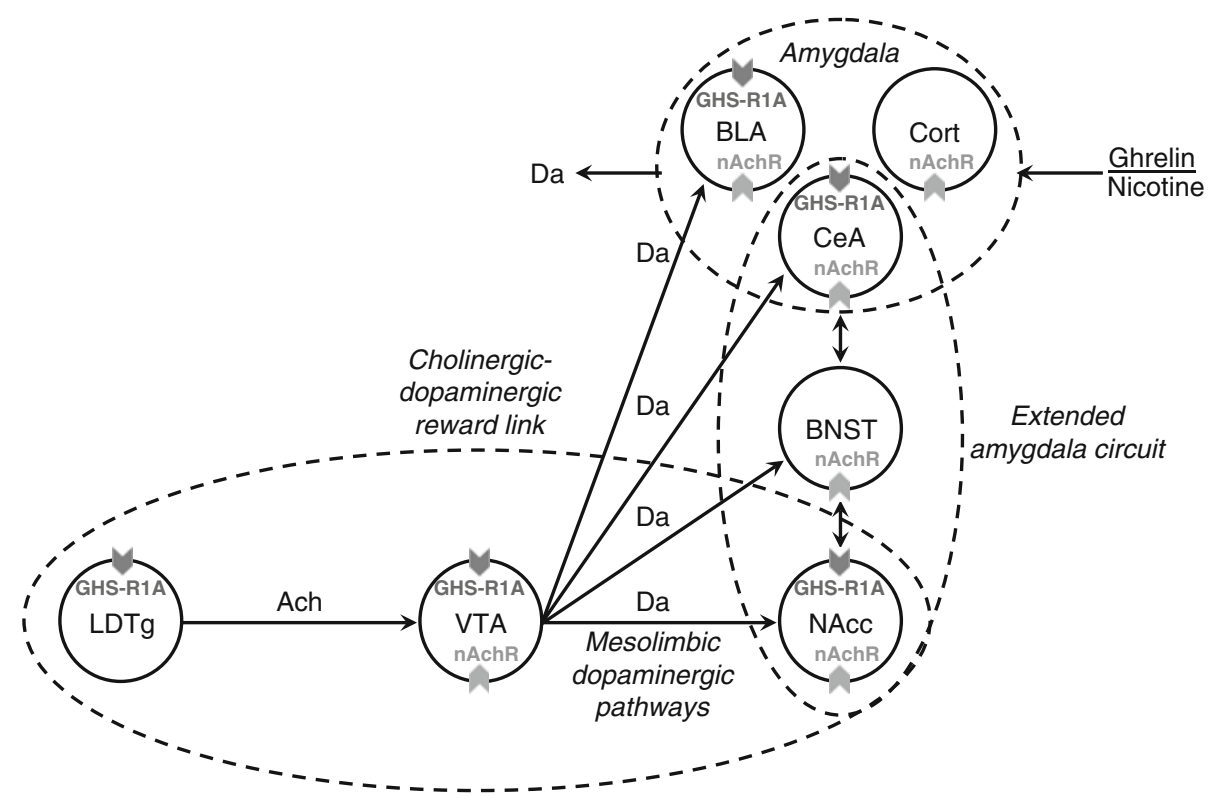

Fig. 4 Ghrelin activates the cholinergic-dopaminergic reward link, represented by the laterodorsal tegmental area $(L D T g)$, the ventral tegmental area (VTA) and the nucleus accumbens (NAcc). Nicotine activates the extended amygdala circuit, represented by the central nucleus of amygdala $(\mathrm{CeA})$, the bed nucleus of stria terminalis (BNST) and the shell of NAcc. Most of these brain regions express ghrelin receptors $(G H S-R 1 A)$ and nicotinic acethylcholine receptors $(n A c h R)$,

only partially. An explanation can be that other receptors, such as NMDA receptors, may be involved in the amygdalar action of nicotine, since nicotine increases NMDA receptor-mediated excitatory postsynaptic currents in rat $\mathrm{CeA}$ slices [38]. Another explanation can be that mecamylamine may also have a partial disinhibitory action on the amygdalar dopamine as the activation of nAchRs increases the frequency of GABAergic inhibitory postsynaptic currents in the BLA [39].

Our experiments demonstrate that ghrelin and nicotine, in single or co-administration, stimulate equally the dopamine release in the amygdala, suggesting the role of both ghrelin and nicotine in drug reward and drug addiction [16, 40, 41]. According to our results the final common pathway should be the activation of cholinergic neurons since the specific cholinergic antagonist was able to block both the ghrelin- and the nicotine-induced dopamine response. Through direct or indirect activation of the $\mathrm{CeA}$ and the BLA ghrelin may increase the incentive value of motivated behaviors, such as reward seeking [16]. However, the intimate mechanism of rewarding action of ghrelin is yet to be elucidated. Our results may have clinical implications. Increased levels of ghrelin may increase the risk of smoking in adolescent females [41]. Moreover, patients with bulimia nervosa have elevated ghrelin levels and higher prevalence for nicotine dependence [42, 43]. Taking all these data into consideration, we share the opinion that as well. Both ghrelin and nicotine, by activating the mesolimbic dopaminergic pathways stimulate the dopamine release from the dopaminergic target areas. Our study demonstrates that ghrelin and nicotine, in single or co-administration, stimulate equally the dopamine release in the amygdala, consisted by the $C e A$, the basolateral $(B L A)$ and the cortical (Cort) nuclei

ghrelin signaling may serve as a novel pharmacological target in the treatment of addictive disorders.

Acknowledgments This work was supported by the following grant: TÁMOP 4.2.2-A-11/1/KONV-2012-0052.

\section{References}

1. Asakawa A, Inui A, Kaga T, Yuzuriha H, Nagata T, Ueno N, Makino S, Fujimiya M, Niijima A, Fujino MA, Kasuga M (2001) Ghrelin is an appetite-stimulatory signal from stomach with structural resemblance to motilin. Gastroenterology 120(2):337-345

2. Kojima M, Hosoda H, Date Y, Nakazato M, Matsuo H, Kangawa $\mathrm{K}$ (1999) Ghrelin is a growth-hormone-releasing acylated peptide from stomach. Nature 402(6762):656-660

3. Guan XM, Yu H, Palyha OC, McKee KK, Feighner SD, Sirinathsinghji DJ, Smith RG, Van der Ploeg LH, Howard AD (1997) Distribution of mRNA encoding the growth hormone secretagogue receptor in brain and peripheral tissues. Brain Res Mol Brain Res 48(1):23-29

4. Ferrini F, Salio C, Lossi L, Merighi A (2009) Ghrelin in central neurons. Curr Neuropharmacol 7(1):37-49. doi:10.2174/15701 5909787602779

5. Chan CB, Cheng CH (2004) Identification and functional characterization of two alternatively spliced growth hormone secretagogue receptor transcripts from the pituitary of black seabream Acanthopagrus schlegeli. Mol Cell Endocrinol 214(1-2):81-95. doi:10.1016/j.mce.2003.11.020

6. Wonnacott S, Sidhpura N, Balfour DJ (2005) Nicotine: from molecular mechanisms to behaviour. Curr Opin Pharmacol 5(1):53-59. doi:10.1016/j.coph.2004.12.002 
7. Glennon RA, Dukat M (2000) Central nicotinic receptor ligands and pharmacophores. Pharm Acta Helv 74(2-3):103-114

8. Balfour DJ (2004) The neurobiology of tobacco dependence: a preclinical perspective on the role of the dopamine projections to the nucleus accumbens [corrected]. Nicotine Tob Res 6(6): 899-912

9. Lecca D, Shim I, Costa E, Javaid JI (2000) Striatal application of nicotine, but not of lobeline, attenuates dopamine release in freely moving rats. Neuropharmacology 39(1):88-98

10. Narayanan NS, Guarnieri DJ, DiLeone RJ (2010) Metabolic hormones, dopamine circuits, and feeding. Front Neuroendocrinol 31(1):104-112. doi:10.1016/j.yfrne.2009.10.004

11. Oades RD, Halliday GM (1987) Ventral tegmental (A10) system: neurobiology. 1. Anatomy and connectivity. Brain Res 434(2): $117-165$

12. Hasue RH, Shammah-Lagnado SJ (2002) Origin of the dopaminergic innervation of the central extended amygdala and accumbens shell: a combined retrograde tracing and immunohistochemical study in the rat. J Comp Neurol 454(1):15-33. doi:10.1002/cne. 10420

13. Inglis FM, Moghaddam B (1999) Dopaminergic innervation of the amygdala is highly responsive to stress. J Neurochem 72(3):1088-1094

14. Dickson SL, Hrabovszky E, Hansson C, Jerlhag E, AlvarezCrespo M, Skibicka KP, Molnar CS, Liposits Z, Engel JA, Egecioglu E (2010) Blockade of central nicotine acetylcholine receptor signaling attenuate ghrelin-induced food intake in rodents. Neuroscience 171(4):1180-1186. doi:10.1016/j.neuro science. 2010.10.005

15. Disse E, Bussier AL, Deblon N, Pfluger PT, Tschop MH, Laville M, Rohner-Jeanrenaud F (2011) Systemic ghrelin and reward: effect of cholinergic blockade. Physiol Behav 102(5):481-484. doi:10.1016/j.physbeh.2010.12.006

16. Jerlhag E, Janson AC, Waters S, Engel JA (2012) Concomitant release of ventral tegmental acetylcholine and accumbal dopamine by ghrelin in rats. PLoS One 7(11):e49557. doi:10.1371/ journal.pone.0049557

17. Blaha CD, Allen LF, Das S, Inglis WL, Latimer MP, Vincent SR, Winn P (1996) Modulation of dopamine efflux in the nucleus accumbens after cholinergic stimulation of the ventral tegmental area in intact, pedunculopontine tegmental nucleus-lesioned, and laterodorsal tegmental nucleus-lesioned rats. J Neurosci 16(2): 714-722

18. Jerlhag E, Egecioglu E, Dickson SL, Andersson M, Svensson L, Engel JA (2006) Ghrelin stimulates locomotor activity and accumbal dopamine-overflow via central cholinergic systems in mice: implications for its involvement in brain reward. Addict Biol 11(1):45-54. doi:10.1111/j.1369-1600.2006.00002.x

19. Lanca AJ, Adamson KL, Coen KM, Chow BL, Corrigall WA (2000) The pedunculopontine tegmental nucleus and the role of cholinergic neurons in nicotine self-administration in the rat: a correlative neuroanatomical and behavioral study. Neuroscience 96(4):735-742

20. Pidoplichko VI, Noguchi J, Areola OO, Liang Y, Peterson J, Zhang T, Dani JA (2004) Nicotinic cholinergic synaptic mechanisms in the ventral tegmental area contribute to nicotine addiction. Learn Mem 11(1):60-69. doi:10.1101/lm.70004

21. Alvarez-Crespo M, Skibicka KP, Farkas I, Molnar CS, Egecioglu E, Hrabovszky E, Liposits Z, Dickson SL (2012) The amygdala as a neurobiological target for ghrelin in rats: neuroanatomical, electrophysiological and behavioral evidence. PLoS One 7(10):e46321. doi:10.1371/journal.pone.0046321

22. Cruz MT, Herman MA, Cote DM, Ryabinin AE, Roberto M (2013) Ghrelin increases GABAergic transmission and interacts with ethanol actions in the rat central nucleus of the amygdala.
Neuropsychopharmacology $\quad 38(2): 364-375 . \quad$ doi:10.1038/npp. 2012.190

23. Goshadrou F, Ronaghi A (2012) Attenuating the effect of Ghrelin on memory storage via bilateral reversible inactivation of the basolateral amygdale. Behav Brain Res 232(2):391-394. doi: 10.1016/j.bbr.2012.03.035

24. Elias WJ, Ray DK, Jane JA (2008) Lennart Heimer: concepts of the ventral striatum and extended amygdala. Neurosurg Focus 25(1):E8. doi:10.3171/FOC/2008/25/7/E8

25. Koob GF, Sanna PP, Bloom FE (1998) Neuroscience of addiction. Neuron 21(3):467-476

26. Watkins SS, Koob GF, Markou A (2000) Neural mechanisms underlying nicotine addiction: acute positive reinforcement and withdrawal. Nicotine Tob Res 2(1):19-37

27. Gaddum JH (1953) The technique of superfusion. Br J Pharmacol Chemother 8(3):321-326

28. Harsing LG Jr, Vizi ES (1984) Release of endogenous dopamine from rat isolated striatum: effect of clorgyline and (-)-deprenyl. Br J Pharmacol 83(3):741-749

29. Pellegrino LJ, Pellegrino AS, Cushman AJ (1979) A stereotaxic atlas of the rat brain, 2nd edn. Plenum Press, New York

30. Jerlhag E, Egecioglu E, Dickson SL, Douhan A, Svensson L, Engel JA (2007) Ghrelin administration into tegmental areas stimulates locomotor activity and increases extracellular concentration of dopamine in the nucleus accumbens. Addict Biol 12(1):6-16. doi:10.1111/j.1369-1600.2006.00041.x

31. Jerlhag E, Egecioglu E, Dickson SL, Svensson L, Engel JA (2008) Alpha-conotoxin MII-sensitive nicotinic acetylcholine receptors are involved in mediating the ghrelin-induced locomotor stimulation and dopamine overflow in nucleus accumbens. Eur Neuropsychopharmacol 18(7):508-518. doi:10.1016/j.euro neuro.2008.02.006

32. Yang Y, Atasoy D, Su HH, Sternson SM (2011) Hunger states switch a flip-flop memory circuit via a synaptic AMPK-dependent positive feedback loop. Cell 146(6):992-1003. doi: 10.1016/j.cell.2011.07.039

33. Marshall DL, Redfern PH, Wonnacott S (1997) Presynaptic nicotinic modulation of dopamine release in the three ascending pathways studied by in vivo microdialysis: comparison of naive and chronic nicotine-treated rats. J Neurochem 68(4):1511-1519

34. Summers KL, Giacobini E (1995) Effects of local and repeated systemic administration of (-)nicotine on extracellular levels of acetylcholine, norepinephrine, dopamine, and serotonin in rat cortex. Neurochem Res 20(6):753-759

35. Shearman E, Rossi S, Sershen H, Hashim A, Lajtha A (2005) Locally administered low nicotine-induced neurotransmitter changes in areas of cognitive function. Neurochem Res 30(8):1055-1066. doi:10.1007/s11064-005-7132-9

36. Koob GF (2013) Theoretical frameworks and mechanistic aspects of alcohol addiction: alcohol addiction as a reward deficit disorder. Curr Top Behav Neurosci 13:3-30. doi:10.1007/7854_ 2011_129

37. Landgren S, Engel JA, Hyytia P, Zetterberg H, Blennow K, Jerlhag E (2011) Expression of the gene encoding the ghrelin receptor in rats selected for differential alcohol preference. Behav Brain Res 221(1):182-188. doi:10.1016/j.bbr.2011.03.003

38. Kenny PJ, Chartoff E, Roberto M, Carlezon WA Jr, Markou A (2009) NMDA receptors regulate nicotine-enhanced brain reward function and intravenous nicotine self-administration: role of the ventral tegmental area and central nucleus of the amygdala.

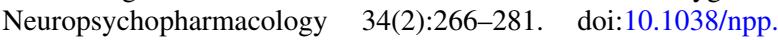
2008.58

39. Zhu PJ, Stewart RR, McIntosh JM, Weight FF (2005) Activation of nicotinic acetylcholine receptors increases the frequency of spontaneous GABAergic IPSCs in rat basolateral amygdala 
neurons. J Neurophysiol 94(5):3081-3091. doi:10.1152/jn.00974. 2004

40. Di Chiara G (2000) Role of dopamine in the behavioural actions of nicotine related to addiction. Eur J Pharmacol 393(1-3): 295-314

41. Picciotto MR (2003) Nicotine as a modulator of behavior: beyond the inverted U. Trends Pharmacol Sci 24(9):493-499. doi: 10.1016/S0165-6147(03)00230-X
42. Austin SB, Gortmaker SL (2001) Dieting and smoking initiation in early adolescent girls and boys: a prospective study. Am J Public Health 91(3):446-450

43. Tanaka $M$, Naruo $T$, Muranaga $T$, Yasuhara $D$, Shiiya $T$, Nakazato M, Matsukura S, Nozoe S (2002) Increased fasting plasma ghrelin levels in patients with bulimia nervosa. Eur $\mathbf{J}$ Endocrinol 146(6):R1-3 